OPEN ACCESS

Edited by:

Baiqing Yuan,

Ludong University, China

Reviewed by:

Matthew A. Addicoat, Nottingham Trent University,

United Kingdom

Hao Huang,

Taiyuan University of

Technology, China

*Correspondence:

Jiahuan Luo

luojiahuan2008@ayit.edu.cn

Shaogang Hou

aydxhsg@163.com

Chuanxiang Zhang

zcx223@hpu.edu.cn

Specialty section:

This article was submitted to

Supramolecular Chemistry,

a section of the journal

Frontiers in Chemistry

Received: 12 August 2020 Accepted: 06 November 2020 Published: 08 December 2020

Citation:

Wang J, Liu S, Luo J, Hou S, Song H, Niu $Y$ and Zhang $C$ (2020) Conductive Metal-Organic Frameworks for Amperometric Sensing of Paracetamol. Front. Chem. 8:594093. doi: 10.3389/fchem.2020.594093

\section{Conductive Metal-Organic Frameworks for Amperometric Sensing of Paracetamol}

\author{
Jing Wang ${ }^{1,2}$, Sen Liu ${ }^{1}$, Jiahuan Luo ${ }^{1 *}$, Shaogang Hou ${ }^{1 *}$, Haixiang Song ${ }^{1}$, Yongsheng Niu ${ }^{1}$ \\ and Chuanxiang Zhang ${ }^{2 *}$
}

${ }^{1}$ Henan Joint International Research Laboratory of Nanocomposite Sensing Materials, School of Chemical and Environmental Engineering, Anyang Institute of Technology, Anyang, China, ${ }^{2}$ Henan Key Laboratory of Coal Green

Conversion, College of Chemistry and Chemical Engineering, Henan Polytechnic University, Jiaozuo, China

An electrochemical sensor for paracetamol is executed by using conductive MOF (NiCu-CAT), which is synthesized by 2, 3, 6, 7, 10, 11-hexahydroxytriphenylene (HHTP) ligand. The utility of this 2D NiCu-CAT is measured by the detection of paracetamol, p-stacking within the MOF layers is essential to achieve high electrical conductivity, redox activity, and catalytic activity. In particular, NiCu-CAT demonstrated detection Limit of determination near $5 \mu \mathrm{M}$ for paracetamol through a wide concentration range $(5-190 \mu \mathrm{M})$. The NiCu-CAT/GCE exhibits excellent reproducibility, stability, and interference for paracetamol.

Keywords: sensor, conductive MOF, NiCu-CAT, amperometric, paracetamol detection

\section{INTRODUCTION}

Paracetamol (PA) is a high effective antipyretic and analgesic drug, which is generally used to relieve moderate pain, such as headache caused by influenza or joint pain, migraine, etc. It regulates the synthesis and release of central prostaglandins by controlling the body temperature in the hypothalamus, improves the pain threshold and plays the role of antipyretic and analgesic (Wan et al., 2009; Ghadimi et al., 2013). The normal dose of paracetamol is harmless to the human body, but excessive or long-term use will lead to liver poisoning, leukemia, or even central nervous system poisoning (Fan et al., 2011). Therefore, it is necessary to develop a sensitive, simple, and rapid detection technology for paracetamol. The existing detection methods include spectrophotometry, titration analysis, chemiluminescence, capillary electrophoresis, fluorescence spectrum, highperformance liquid chromatography (Easwaramoorthy et al., 2001; Bosch et al., 2006). However, it is not suitable for the rapid detection of PA in daily life due to the complex pretreatment, large equipment, time-consuming and expensive of these existing detection methods. On the contrary, electrochemical methods have the advantages of being simple and convenient, highly sensitive, quickly responsive, low in cost and highly selective (Yan et al., 2019; Yuan et al., 2019, 2020; Ma et al., 2020; Wang et al., 2020). In addition, PA is an electroactive substance that is prone to electrochemical oxidation, so the detection of PA by electrochemical sensors has aroused great interest. However, the redox reaction of PA on the bare electrode is slow. As a result, researchers have developed high catalytic activity nanomaterials for the design of highly sensitive paracetamol electrochemical sensors (Ejaz and Jeon, 2017; Raymundo-Pereira et al., 2017; Zhao et al., 2019).

In recent decades, nanomaterials have attracted worldwide attention and have been widely used to modify electrochemical sensing electrodes. As one of the most popular materials at present, 
the conductive nano-Metal Organic Framework (MOFs) (Campbell and Dincă, 2017; Biswas et al., 2020; Ko et al., 2020; Suwannakot et al., 2020) have many advantages, such as simple synthesis process, environmental friendliness, adjustable structure and so on, especially its excellent conductivity, which has attracted extensive attention (Ko et al., 2017; Fang et al., 2018; Xie et al., 2020). Metal-catecholates (M-CATs) are a kind of conductive MOF composed of HHTP ligands and central metal ions (Miner et al., 2018; Zhang et al., 2018, 2019; Guo et al., 2019). The good conductivity of M-CATs is mainly due to its special structure, in which oxygen atoms in an HHTP ligand can also combine with axial water ligands to form hydrogen bonds. M-CATs show two accumulation modes: one kind, a two-dimensional layered framework with a hexagonal hole and honeycomb structure, is formed by oxygen and p-p interaction, where metal nodes and organic ligands serving as charge carriers enable full charge delocalization in the two-dimensional (2D) plane, so as to produce good electrical conductivity, and the other is along the $c$ axis through hydrogen bonding accumulation, which is easy to form one-dimensional (1D) structures between layers. Because of their special porous structure and good electrical conductivity, M-CATs have great prospects for related applications such as catalysis, supercapacitors and electrical analysis.
In this paper, the $2 \mathrm{D}$ conductive nano-MOFs are first systematically studied for the detection of PA in multicomponent aqueous solutions. The sensor has the characteristics of fast electronic transfer, good catalytic performance, and good detection limit of determination for paracetamol. Hence this work opens up a new method for electrochemical detection of paracetamol, which is beneficial to the study of the redox metabolism of paracetamol in aqueous solution and expands the application of MOF nanomaterials in electroanalytical chemistry.

\section{METHODS AND MATERIALS}

\section{Materials and Reagents}

The chemical 2, 3, 6, 7, 10, 11-heahydroxytriphenylene (HHTP) was purchased from Innochem Reagents (Shanghai, China); Nickel (II) acetate tetrahydrate $\left(\mathrm{Ni}(\mathrm{OAc})_{2} \cdot 4 \mathrm{H}_{2} \mathrm{O}\right)$, Copper (II) acetate tetrahydrate $\left(\mathrm{Cu}(\mathrm{OAc})_{2} \cdot 4 \mathrm{H}_{2} \mathrm{O}\right)$, standard paracetamol, dopamine (DA), and ascorbic acid (AA) were purchased from Aladdin (Shanghai, China). All other chemicals were analytical reagent grade. Deionized water was prepared from a Milli-Q water purification system. Different $\mathrm{pH}$ phosphate buffers $\left(0.1 \mathrm{~mol} \mathrm{~L}^{-1}\right)$ were prepared by mixing $\mathrm{KH}_{2} \mathrm{PO}_{4}\left(0.1 \mathrm{~mol} \mathrm{~L} \mathrm{~L}^{-1}\right)$ and $\mathrm{Na}_{2} \mathrm{HPO}_{4}(0.1 \mathrm{~mol}$ $\left.\mathrm{L}^{-1}\right)$ solutions.

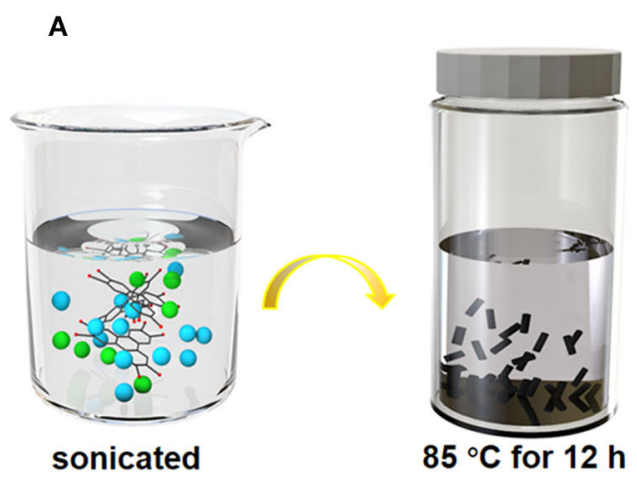

c

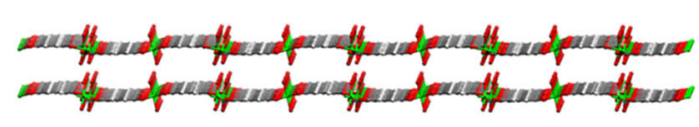

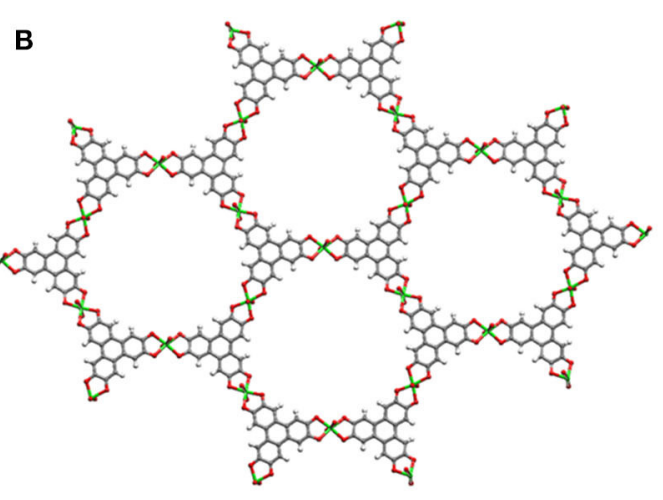

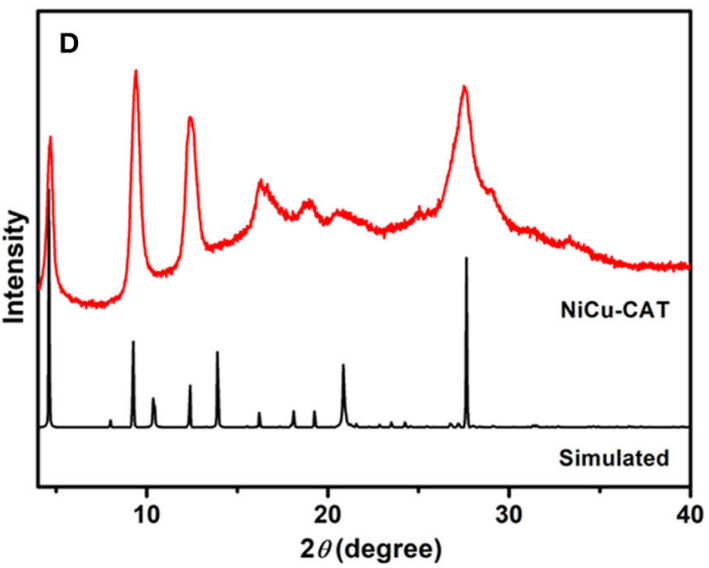

FIGURE 1 | (A) Schematic illustration of the preparation of NiCu-CAT. (B) Connecting mode of HHTP molecules and $\mathrm{Ni}^{2+}$ and Cu²+ ions. (C) View of the two extended corrugated layers along the [110] direction. (D) XRD pattern of NiCu-CAT nanocrystal and simulated. 


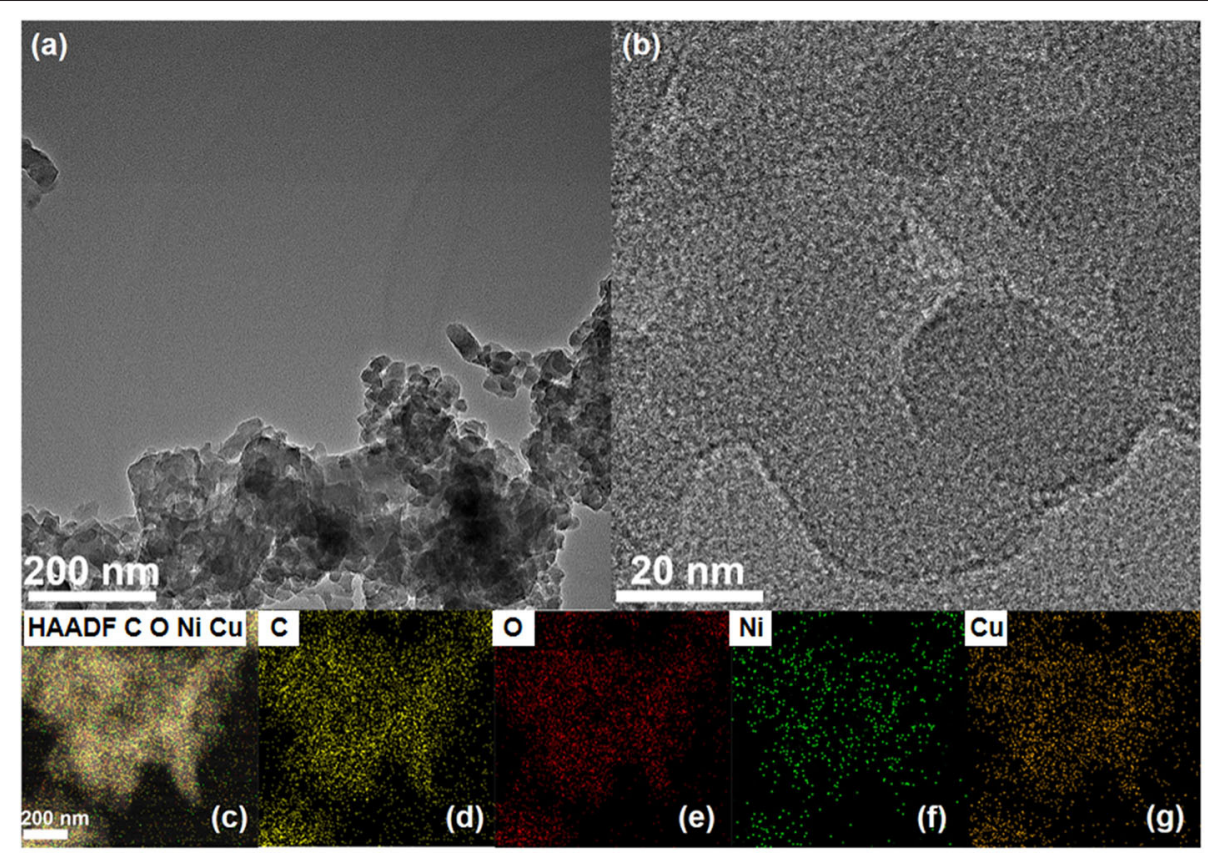

FIGURE 2 | (a,b) TEM images of the NiCu-CAT nanocrystal. (c-g) The distribution images of various elements of NiCu-CAT nanocrystal.

\section{Instrumentation}

All chemicals were obtained from commercial sources and used without further purification. Powder X-ray diffraction (PXRD) data were collected on a Rigaku D/max-2,550 diffractometer with $\mathrm{CuK} \alpha$ radiation $(\lambda=1.5418 \AA$ ). The infrared (IR) spectra were recorded within the $4,000-500 \mathrm{~cm}^{-1}$ region on a Nicolet Impact 410 FTIR spectrometer with $\mathrm{KBr}$ pellets. TEM, HAADFSTEM, HRTEM, and EDX were carried out on a FEI Talos F200S TEM $(200 \mathrm{kV})$. The structure for $\mathrm{NiCu}-\mathrm{CAT}$ was simulated by Materials Studio 8.0 and using the Crystallographic Information File (CIF) of Ni-CAT (Ko et al., 2020) as mode.

\section{Synthesis of the NiCu-CAT Nanocomposite}

Typically, $30 \mathrm{mg}$ of $\mathrm{Ni}(\mathrm{OAc})_{2} \cdot 4 \mathrm{H}_{2} \mathrm{O}, 20 \mathrm{mg}$ of $\mathrm{Cu}(\mathrm{OAc})_{2} \cdot 4 \mathrm{H}_{2} \mathrm{O}$, and $42 \mathrm{mg}$ of HHTP ligands were dissolved in $9 \mathrm{~mL}$ of a solvent mixture of deionized water. The vial was capped and sonicated for $30 \mathrm{~min}$ until the solid was dissolved, and after that $0.5 \mathrm{~mL}$ of NMP was added drop-wise into this solution, and then this solution continue was sonicated for $10 \mathrm{~min}$, the reaction mixture was transferred into an isothermal oven at $85^{\circ} \mathrm{C}$ for $12 \mathrm{~h}$. After the crystals were washed with deionized water and acetone, the $\mathrm{NiCu}-\mathrm{CAT}$ was obtained.

\section{Preparation of the Modified Electrodes}

First of all, glassy carbon electrode (GCE) was mechanically polished on a velvet cloth with $0.05 \mu \mathrm{M}$ alumina slurry. Secondly, then electrochemical polishing was carried out in a potential window of $0-1 \mathrm{~V}$ at a scanning speed of $100 \mathrm{mV} / \mathrm{s}$ in $0.1 \mathrm{M}$ $\mathrm{H}_{2} \mathrm{SO}_{4}$. Thirdly, GCE was ultrasonicated in deionized water and ethanol for $5 \mathrm{~s}$ respectively. One milligram of $\mathrm{NiCu}-\mathrm{CAT}$ was dispersed in $1 \mathrm{~mL}$ of distilled water and Nafion (5 wt\%) and ultrasonicated by cell disrupter for $30 \mathrm{~min}$ to ensure a uniform dispersion. Then, $6 \mu \mathrm{L}$ of this dispersion was dropped on cleaned GCE and dried at room temperature to obtain a suitable coating ( $\mathrm{NiCu}-\mathrm{CAT} / \mathrm{GCE})$.

\section{Electrochemical Measurements}

Cyclic voltammetry (CV), electrochemical impedance spectroscopy (EIS) and differential pulse voltammetry (DPV) were carried out with a CHI760E electrochemical workstation (Shanghai Chenhua Instrument Co. Ltd., China) using a threeelectrode system, with a bare or modified glassy carbon electrode (GCE, $3.0 \mathrm{~mm}$ in diameter) as the working electrode. A platinum $(\mathrm{Pt})$ wire and $\mathrm{Ag} / \mathrm{AgCl}$ were the counter and reference electrodes, respectively. All electrochemical experiments were conducted at room temperature $\left(25^{\circ} \mathrm{C}\right)$.

\section{RESULTS}

\section{Characterization}

Typically, NiCu-CAT constructed from a 2D hexagonal lattice in the $a b$-plane, which configurations along the [001] direction, are synthesized by solvothermal method (Figure 1A). As shown in Figures 1B,C, the divalent metal ions $\left(\mathrm{M}^{2+}\right)$ are matched to adjacent deprotonated HHTP ligands to form an extended 2D Pconjugation honeycomb framework. Each ligand can be oxidized to achieve charge balance with the metal ion centers, which is very important to improve the charge density of the $\mathrm{M}_{3}(\mathrm{HHTP})_{2}$ $\left(\mathrm{H}_{2} \mathrm{O}\right)_{12}$ (Supplementary Figures 1a,b).

The X-ray diffraction (XRD) patterns of NiCu-CAT that matched reported characterization are shown in Figure 1D. The XRD pattern of $\mathrm{NiCu}$-CAT clearly reveals three sharp intense 

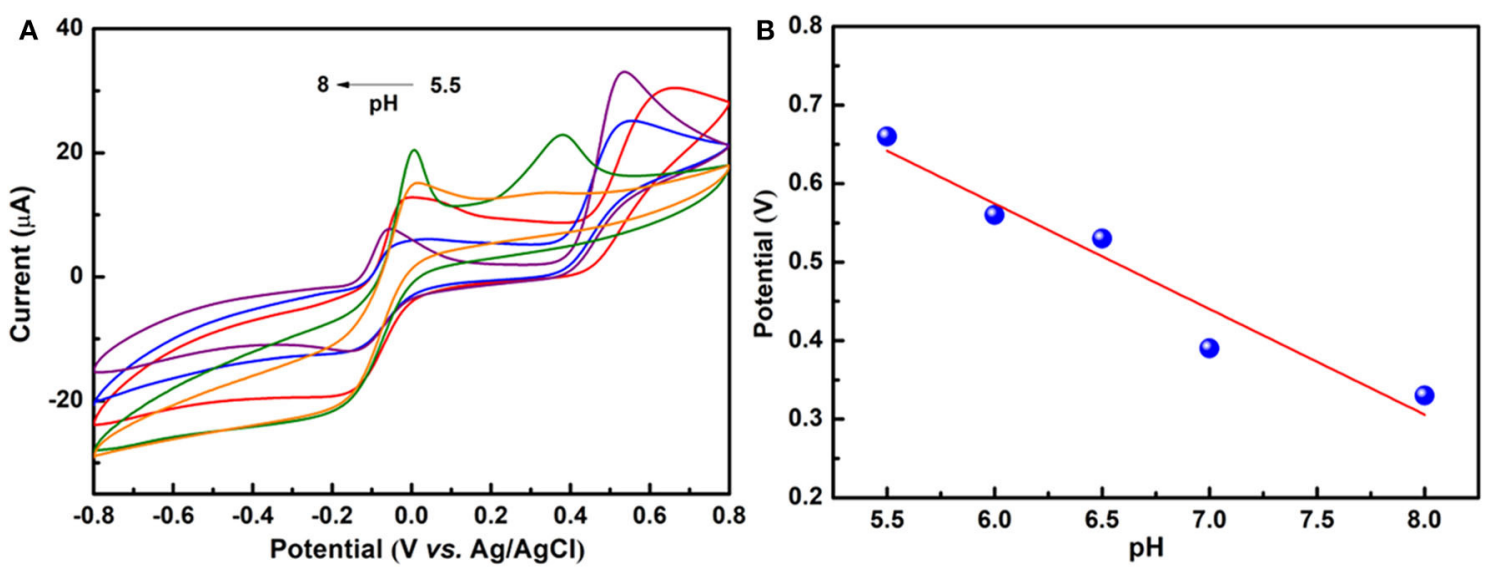

FIGURE 3 | (A) CV curves of $50 \mu \mathrm{M}$ paracetamol at the NiCu-CAT/GCE in $0.1 \mathrm{M}$ PBS under 5.5, 6, 6.5, 7, 8 pH values. (B) The relationship between pH and peak potential.
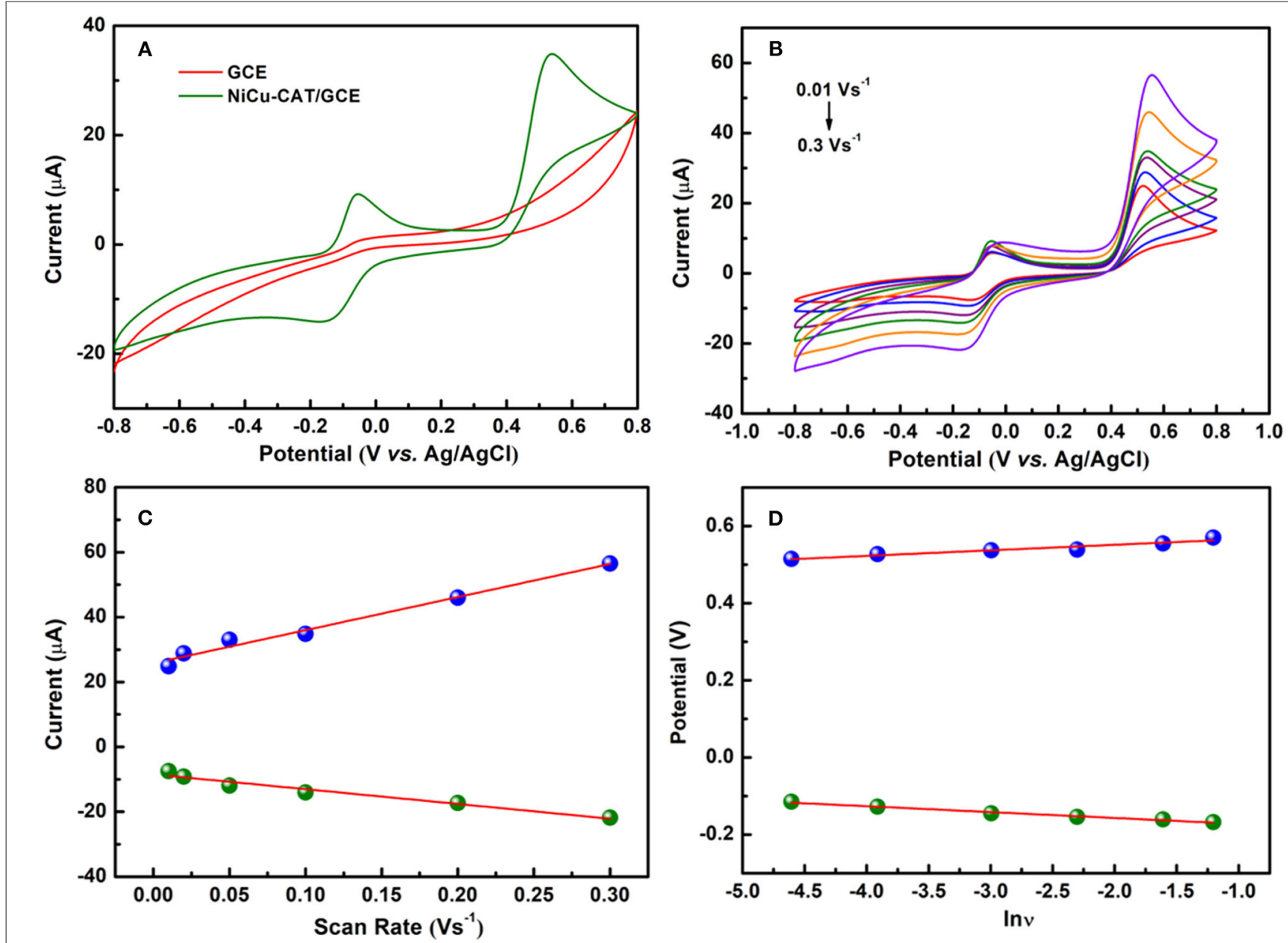

FIGURE 4 | (A) CVs of GCE and NiCu-CAT/GCE in presence of $40 \mu \mathrm{M}$ paracetamol. (B) CVs of $40 \mu \mathrm{M}$ paracetamol on NiCu-CAT/GCE at scan rates of 10, 20, 50, 100, 200, and $300 \mathrm{mVs}^{-1}$. (C) Displays the plot of the peak current vs. scan rates. (D) Displays the plot of the peak potential vs. Inv. 
peaks of (100), (200) and (210) planes at $2 \theta=4.7^{\circ}, 9.5^{\circ}$, and $12.4^{\circ}$, respectively. The peaks indicate the long-range order of the nanocrystal in the $a b$-plane (Miner et al., 2018; Guo et al., 2019; Ko et al., 2020). Fourier transform infrared spectroscopy (FT-IR) is conducted, as showed in Supplementary Figure 2. Typically, the bonds at $1,118,1,430$, and $3,099 \mathrm{~cm}^{-1}$ are attributed to the $-\mathrm{C}=\mathrm{C}$ - stretching, $-\mathrm{C}-\mathrm{O}$ - stretching vibration, and $-\mathrm{O}-\mathrm{H}$, respectively. The bands at 672 and $804 \mathrm{~cm}^{-1}$ represent the outof-plane $\mathrm{C}-\mathrm{H}$ bending modes, fully manifesting the existence of organic HHTP.

Transmission electron microscopy (TEM), high-angle annular dark-field scanning TEM (HAADF-STEM), and high-resolution transmission electron microscopy (HRTEM) were executed to characterize the morphology of $\mathrm{NiCu}$ CAT. As shown in Figures $\mathbf{2 a}, \mathbf{b}, \mathrm{NiCu}-\mathrm{CAT}$ is made up of nanocrystals with the diameter of $20-50 \mathrm{~nm}$. The corresponding energy dispersive X-ray spectroscopy (EDX) mapping images (Figures 2c-g and Supplementary Figure 4) evidence the even distribution of elemental $\mathrm{Ni}, \mathrm{Cu}, \mathrm{C}$, and $\mathrm{O}$ throughout the nanocrystal.

\section{Effect of the pH Values}

Electrochemical properties were investigated with the conventional three-electrode system, as mentioned in the Methods and Materials section. The effect of $\mathrm{pH}$ on the peak potential of PA using cyclic-voltammetry in $0.1 \mathrm{M} \mathrm{PBS}$ at $\mathrm{pH}$ values of 5.5 to 8.0 is presented in Figure 3A. The effect of the $\mathrm{pH}$ value of the PBS on peak potential of $50 \mu \mathrm{M}$ PA at $\mathrm{NiCu}-\mathrm{CAT} / \mathrm{GCE}$ is also investigated. It can be seen that with the $\mathrm{pH}$ increased, the oxidation peak shifted to a negative potential, indicating that this observation can be interpreted by observing the protons in the electrochemical reactions. The $\mathrm{pH}$ value 6.5 is chosen for further PA detection, with the highest sensitivity. In addition, Figure 3B shows that for a linear relationship between the peak potential $\left(E_{\mathrm{pa}}\right)$ and $\mathrm{pH}$ value, the regression equation is shown by the following expression (Afkhami et al., 2004):

$$
\mathrm{Epa}(\mathrm{V})=\mathrm{Epa}(\mathrm{pH}=0)-(2.303 m \mathrm{RT} / n \mathrm{~F}) * \mathrm{pH}
$$

where $E_{\mathrm{pa}}(\mathrm{pH}=0)$ is the oxidation potential for paracetamol, $\mathrm{R}$ is the gas constant $\left(8.314 \mathrm{~J} \cdot \mathrm{K} \mathrm{mol}^{-1}\right), \mathrm{F}$ is Faraday's constant $\left(96485 \mathrm{C} \mathrm{mol}^{-1}\right), \mathrm{T}$ is the Kelvin temperature $(298.15 \mathrm{~K}), n$ is the number of electrons transferred, and $m$ is the number of protons involved in the reaction. From Figure 3B, $E_{\mathrm{pa}}$ decreased with a slope of $-47.5 \mathrm{mV} / \mathrm{pH}(R=0.98802)$. Furthermore, from this equation, according to $\mathrm{d} E_{\mathrm{pa}} / \mathrm{dpH}=$ $-2.303 \mathrm{mRT} / n \mathrm{~F}$ (Kang et al., 2010). Obviously, the redox reaction involves the same protons and number of electrons with a ratio of 1:1 (Fanjul-Bolado et al., 2009; Kalambate et al., 2015).

\section{Electrocatalytic Behavior of Paracetamol}

Cyclic voltammetry for $\mathrm{NiCu}-\mathrm{CAT} / \mathrm{GCE}$ is performed to investigate the electrochemical behavior of $40 \mu \mathrm{M}$ paracetamol, electrodes are cycled between -0.8 and $0.8 \mathrm{~V}$ at a scan rate of $100 \mathrm{mV} / \mathrm{s}$. Figure $4 \mathrm{~A}$ shows $\mathrm{CV}$ responses of

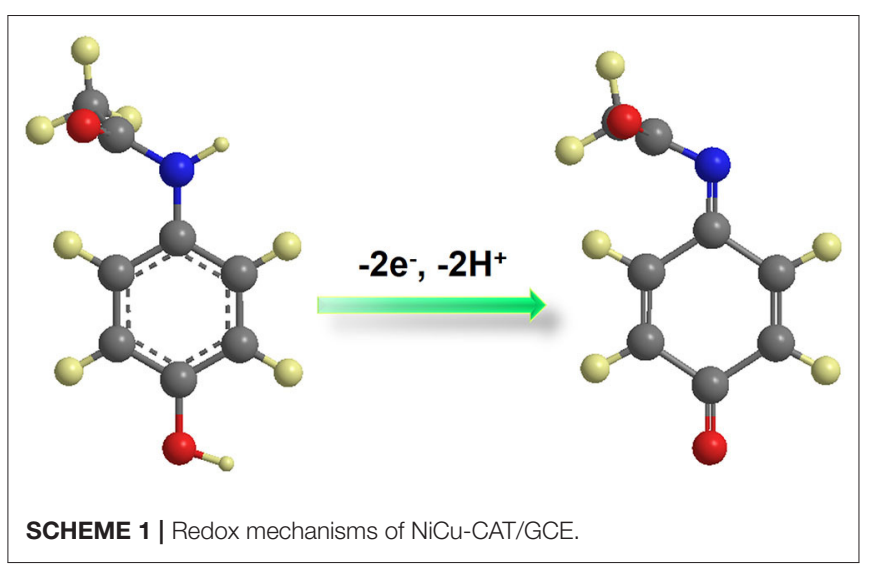

GCE and NiCu-CAT /GCE in PBS ( $\mathrm{pH}=6.5$ ). No redox peaks are observed at GCE, which means that GCE is not electroactive in the studied potential region. In contrast, the redox peaks of $\mathrm{NiCu}-\mathrm{CAT} / \mathrm{GCE}$ appeared at -0.14 and $0.53 \mathrm{~V}$, respectively, which can be attributed to the electrochemical redox process of the $\mathrm{NiCu}$-CAT nanocrystals, and the current is larger than that of the bare glassy carbon electrode. The results show that $\mathrm{NiCu}-\mathrm{CAT}$ has a good electrocatalytic effect on PA. Due to the special mesoporous structure of $\mathrm{NiCu}-\mathrm{CAT}$, the conductivity of the electrode is improved and the electrocatalytic effect of the electrode on PA is enhanced.

\section{Effect of the Potential Scan Rate}

In order to investigate the mechanisms responsible for the oxidation of PA at NiCu-CAT/GCE, cyclic voltammograms of $\mathrm{PA}$ were recorded at various scan rates. It was observed that the cathodic peak current $\left(I_{\mathrm{pc}}\right)$ and anodic peak current $\left(I_{\mathrm{pa}}\right)$ increase linearly with the scan rate over the range of 10-300 $\mathrm{mVs}^{-1}$ for and PA. Figure 4B shows that the peak potential shifts forward with the increase of scanning rate. The linear relationship between the scan rate and peak current can be expressed by a linear regression equation (Raymundo-Pereira et al., 2016) as $I_{\mathrm{pa}}[\mu \mathrm{A}]=101.88 \nu\left[\mathrm{Vs}^{-1}\right]-0.25,\left(R^{2}=0.980\right)$ and $I_{\mathrm{pc}}[\mu \mathrm{A}]=-45.45 v\left[\mathrm{Vs}^{-1}\right]-8.471\left(\mathrm{R}^{2}=0.957\right)$ for the $\mathrm{NiCu}-\mathrm{CAT} / \mathrm{GCE}$ electrode, respectively (Figure 4C). The results show that $\mathrm{PA}$ undergoes an adsorption-controlled reaction (Goyal et al., 2010; Arvand and Gholizadeh, 2012; Kutluay and Aslanoglu, 2013).

To investigate the reaction kinetics, as shown in Figure 4D, the anodic and cathodic peak potentials have linear relationships with the natural logarithm of the scan rate $(\ln v)$. The linear regression equations are found to be:

$$
\begin{aligned}
& \operatorname{Epa}(\mathrm{V})=0.020 \ln v\left(\frac{\mathrm{V}}{\mathrm{s}}\right)+\mathbf{0 . 5 8 0},\left(\mathrm{R}^{2}=\mathbf{0 . 9 5 3 5}\right) \\
& \operatorname{Epc}(\mathrm{V})=-0.019 \ln v\left(\frac{\mathrm{V}}{\mathrm{s}}\right)-\mathbf{0 . 5 8 0},\left(\mathrm{R}^{2}=\mathbf{0 . 9 8 5 9}\right)
\end{aligned}
$$

According to Laviron's model (Laviron, 1974, 1979), the number of the electron-transfer $(n)$ and charge-transfer coefficient $(\alpha)$ 

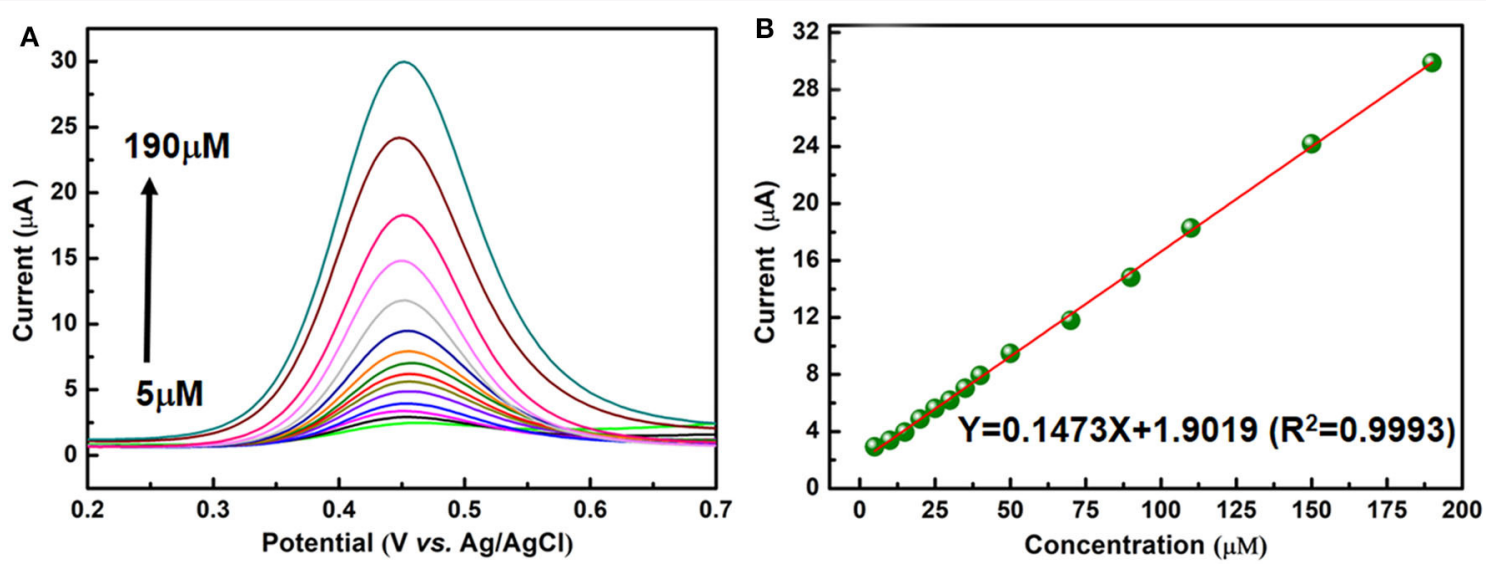

FIGURE 5 | (A) DPV responses for different paracetamol concentrations (5, 10, 15, 20, 25, 30, 35, 40, 50, 70, 90, 110, 150, and 190 $\mu \mathrm{M})$ on a NiCu-CAT/GCE. (B) The linear relationship between the peak current and paracetamol concentration.
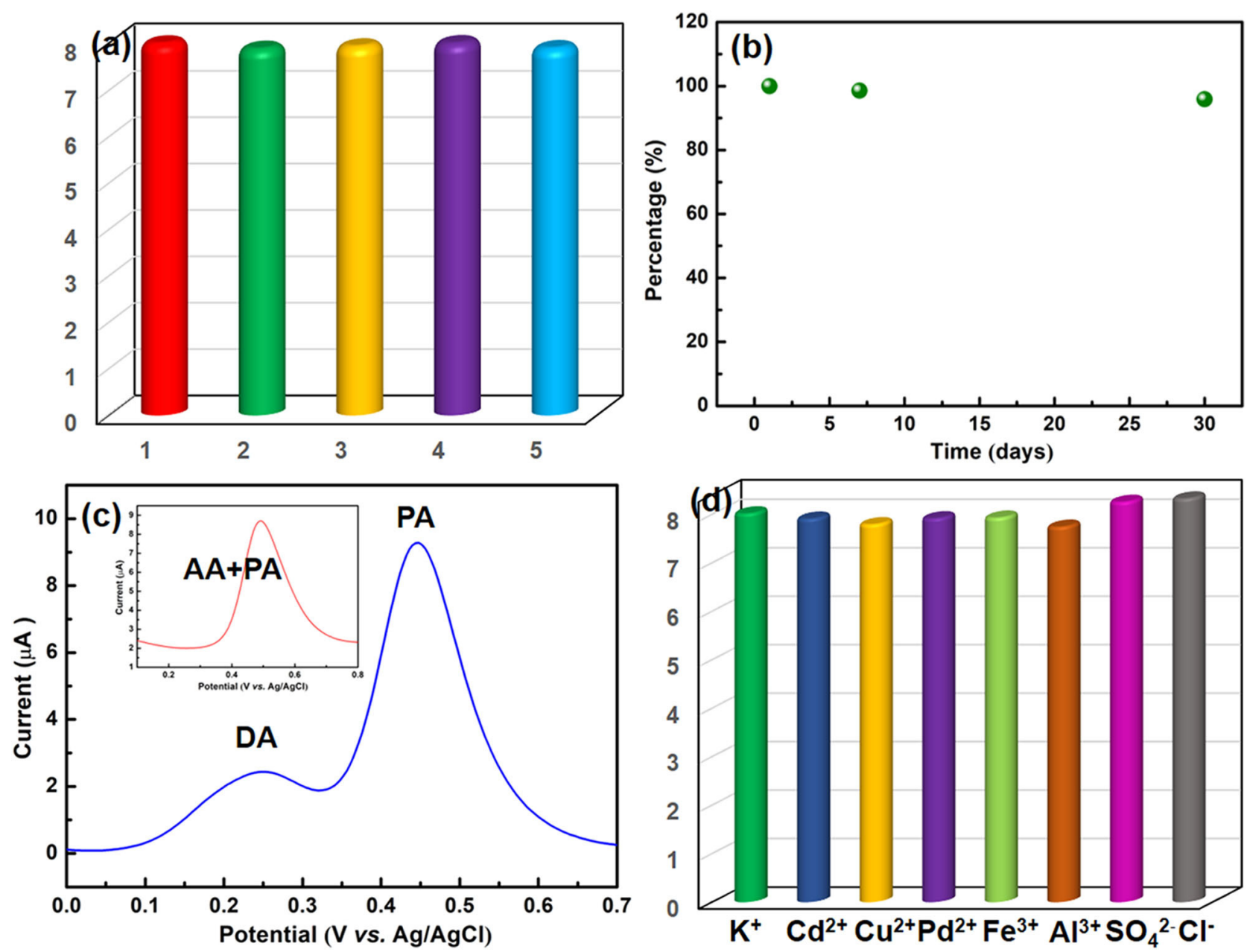

FIGURE 6 | (a) Evaluation of repeatability. (b) Stability of the NiCu-CAT/GCE after pretreatment during 30 days. (c) DPV responses of the NiCu-CAT/GCE in PBS (0.1 M, pH 6.5) containing $40 \mu \mathrm{M}$ PA and $200 \mu \mathrm{M} \mathrm{DA}$; inset is the containing $40 \mu \mathrm{M}$ PA and $200 \mu \mathrm{M}$ AA, respectively. (d) Effects of the presence of inorganic ions on the voltammetric responses of $40 \mu \mathrm{M}$ paracetamol using the NiCu-CAT/GCE. 
can be calculated to be 2 and 0.50 , respectively. According to the above equations, results show that there is a two-proton and twoelectron process for the PA electro-oxidation at $\mathrm{NiCu}-\mathrm{CAT} / \mathrm{GCE}$. The possible redox mechanisms are as follows in Scheme $\mathbf{1 .}$

\section{Analytical Performance Characteristics}

DPV is utilized to measure the PA peak current on the present electrochemical sensor. This method has the advantages of high sensitivity and good resolution. Under optimized experimental conditions, the anodic peak current is directly proportional to the concentration of PA from 5 to $190 \mu \mathrm{M}$ as shown in Figure 5A. From Figure 5B, it can be seen that the peak current of PA is in a linear dynamic range with its concentration. The regression equation (Goyal and Singh, 2006; Krampa et al., 2018; $\mathrm{Xu}$ et al., 2019) for the region is $I_{\mathrm{pa}}(\mu \mathrm{A})=0.1473 c(\mu \mathrm{M})+$ $1.9019\left(R^{2}=0.9993\right)$, the limit of determination is near $5 \mu \mathrm{M}$. The limit of determination of the $\mathrm{NiCu}-\mathrm{CAT} / \mathrm{GCE}$ is similar to some electrochemical sensors reported using electrochemical method for detecting paracetamol (Fu et al., 2015, 2018a,b). As shown in Supplementary Figure 7, the diameter of the paracetamol is $8.3 \AA^{*} 3.7 \AA$, and the pore size of the $\mathrm{Ni} / \mathrm{Cu}$ CAT is $13 \AA$. The paracetamol could easily go into the channel; consequently, we expected that the effects between the $\mathrm{Ni} / \mathrm{Cu} \mathrm{CAT}$ and paracetamol were based on host-guest interaction (Ko et al., 2017; Fang et al., 2018; Xie et al., 2020).

\section{DISCUSSION}

\section{Reproducibility, Stability and Interference}

The peak currents of five tests were recorded to study the reproducibility of the $\mathrm{NiCu}-\mathrm{CAT} / \mathrm{GCE}$ by $\mathrm{DPV}$, and the same electrode was modified five times for PA detection at the same concentration of $40 \mu \mathrm{M}$ (Figure 6a). Under the optimized conditions, the relative standard deviation (RSD) is $1.01 \%$, indicating that $\mathrm{NiCu}-\mathrm{CAT} / \mathrm{GCE}$ can obtain satisfactory repeatability.

In order to study the stability of the modified GCE, the $\mathrm{NiCu}$ CAT/GCE is used to measure $40 \mu \mathrm{M}$ paracetamol in PBS $(0.1 \mathrm{~mol}$ $\mathrm{L}^{-1}, \mathrm{pH}=6.5$ ) after being stored in the air for 7 days and 30 days, respectively (Figure 6b and Supplementary Figure 5). The fabricated sensors retain more than $95.8 \%$ of their original responses, indicating that $\mathrm{NiCu}-\mathrm{CAT} / \mathrm{GCE}$ has good stability. This stability is helpful to the application of chemically modified electrode in electroanalysis.

To investigate the sensor selectivity, the modified GCE is used to detect paracetamol in the presence of interferents. In addition, it was found that the peak current of $40 \mu \mathrm{M}$ PA is not affected in the presence of 5 -folds of dopamine (DA) and ascorbic acid (AA) (Figure 6c), and 100-fold excess concentrations of $\mathrm{K}^{+}$, $\mathrm{Cd}^{2+}, \mathrm{Cu}^{2+}, \mathrm{Pb}^{2+}, \mathrm{Fe}^{3+}, \mathrm{Al}^{3+}, \mathrm{SO}_{4}^{2-}$, and $\mathrm{Cl}^{-}$(Figure 6d). The results demonstrated that the potential interfering substances did not interfere with the $40 \mu \mathrm{M}$ paracetamol signals, indicating that the present assay offers good sensitivity for determining paracetamol.

\section{Real Sample Analysis}

In this paper, the $\mathrm{NiCu}$-CAT electrochemical sensor was prepared to detect paracetamol in actual samples. The commercial tablet (Tylenol, produced in Shanghai, China) with a nominal value of $650 \mathrm{mg}$ was used for the analysis of paracetamol. The tablets were pre-treated by grinding, dissolving with ethanol, filtering, and then diluting them with a phosphate buffer solution. The test results are shown in Supplementary Table 1. The recoveries of the tests were in the range from 97.23 to $103.8 \%$. indicating that the modified electrode has a good detection performance for the actual samples containing PA, which is expected to be used for the detection of PA in real life.

\section{CONCLUSION}

In summary, we have successfully constructed $2 \mathrm{D}$ conductive metal-organic frameworks as efficient electrocatalysts to achieve electrochemical detection of PA in aqueous solutions. The $\mathrm{NiCu}-\mathrm{CAT}$ possesses a specifically big pore, numerous potential active sites, good electrical conductivity and water stability. The electrochemical properties of $\mathrm{NiCu}-\mathrm{CAT} / \mathrm{GCE}$ for PA were studied by cyclic voltammetry and the differential pulse method, under the optimal experimental conditions, the modified electrode has a wide linear range $(5-190 \mu \mathrm{m})$ for the electrochemical detection of PA with good reproducibility and stability, and it also achieved the limit of determination near $5 \mu \mathrm{M}$. The research on the electrochemical detection of PA provides a platform for the application of MOF composites in electroanalysis, which is an excellent electrochemical method for pharmaceutical analysis.

\section{DATA AVAILABILITY STATEMENT}

All datasets generated for this study are included in the article/Supplementary Material.

\section{AUTHOR CONTRIBUTIONS}

JW executed the whole synthesis progress and paper writing. SL tested the samples of XRD and TEM. JL, SH, HS, YN, and CZ charged for data processing and result discussion. All authors contributed to the article and approved the submitted version.

\section{FUNDING}

This work was financed by the National Natural Science Foundation of China (Grant No. 21801005, 21901008), the key scientific research project plan of Henan Province Colleges and universities (19A150012, 19A480003), the scientific and technological project of Henan province (192102310232), the Henan postdoctoral Foundation (1901020), Innovation Practice Base for Post-doctoral of Anyang Institute of Technology (402010), and Huanshui Scholars development plan of Anyang Institute of Technology. 


\section{ACKNOWLEDGMENTS}

Thanks to the Test Center of the School of Chemical and Environmental Engineering, Anyang Institute of Technology and the editors and reviewers.

\section{REFERENCES}

Afkhami, A., Nematollahi, D., Khalafi, L., and Rafiee, M. (2004). Kinetic study of the oxidation of some catecholamines by digital simulation of cyclic voltammograms. Int. J. Chem. Kinet. 37, 17-24. doi: 10.1002/kin.20046

Arvand, M., and Gholizadeh, T. M. (2012). Simultaneous voltammetric determination of tyrosine and paracetamol using a carbon nanotubegraphene nanosheet nanocomposite modified electrode in human blood serum and pharmaceuticals. Colloid. Surfaces B. 103, 84-93. doi: 10.1016/j.colsurfb.2012.10.024

Biswas, S., Chen, Y., Xie, Y., Sun, X., and Wang, Y. (2020). Ultrasmall Au (0) inserted hollow PCN-222 MOF for the high-sensitive detection of estradiol. Anal. Chem. 92, 4566-4572. doi: 10.1021/acs.analchem. $9 \mathrm{~b} 05841$

Bosch, M. E., Sánchez, A. J. R., Rojas, F. S., and Ojeda, C. B. (2006). Determination of paracetamol: historical evolution. J. Pharmaceut. Biomed. 42, 291-321. doi: 10.1016/j.jpba.2006.04.007

Campbell, M. G., and Dincă M. (2017). Metal-organic frameworks as active materials in electronic sensor devices. Sensors 17:1108. doi: 10.3390/s17051108

Easwaramoorthy, D., Yu, Y.-C., and Huang, H.-J. (2001). Chemiluminescence detection of paracetamol by a luminol-permanganate based reaction. Anal. Chim. Acta 439, 95-100. doi: 10.1016/S0003-2670(01)00968-0

Ejaz, A., and Jeon, S. (2017). A highly stable and sensitive GO-XDA$\mathrm{Mn}_{2} \mathrm{O}_{3}$ electrochemical sensor for simultaneous electrooxidation of paracetamol and ascorbic acid. Electrochim. Acta 245, 742-751. doi: 10.1016/j.electacta.2017.05.193

Fan, Y., Liu, J.-H., Lu, H.-T., and Zhang, Q. (2011). Electrochemical behavior and voltammetric determination of paracetamol on $\mathrm{Nafion} / \mathrm{TiO}_{2}$ graphene modified glassy carbon electrode. Colloid. Surfaces B. 85, 289-292. doi: 10.1016/j.colsurfb.2011.02.041

Fang, X., Zong, B., and Mao, S. (2018). Metal-organic framework-based sensors for environmental contaminant sensing. Nano-Micro Lett. 10:64. doi: 10.1007/s40820-018-0218-0

Fanjul-Bolado, P., Lamas-Ardisana, P. J., and Hernández-Santos, D., and Costa-García A. (2009). Electrochemical study and flow injection analysis of paracetamol in pharmaceutical formulations based on screen-printed electrodes and carbon nanotubes. Anal. Chim. Acta 638, 133-138. doi: 10.1016/j.aca.2009.02.019

Fu, L., Lai, G., and Yu, A. (2015). Preparation of $\beta$-cyclodextrin functionalized reduced graphene oxide: application for electrochemical determination of paracetamol. RSC Adv. 5, 76973-76978. doi: 10.1039/C5RA12520K

Fu, L., Wang, A., Lai, G., Lin, C. T., Yu, J., Yu, A., et al. (2018a). A glassy carbon electrode modified with $\mathrm{N}$-doped carbon dots for improved detection of hydrogen peroxide and paracetamol, Mikrochim Acta 185:87. doi: 10.1007/s00604-017-2646-9

Fu, L., Xie, K., Zheng, Y., Zhang, L., and Su, W. (2018b). Graphene ink film based electrochemical detector for paracetamol analysis. Electronics 7:15. doi: 10.3390/electronics7020015

Ghadimi, H. M. A., Tehrani, R., Ali, A. S. M., Mohamed, N., and Ab Ghani, S. (2013). Sensitive voltammetric determination of paracetamol by poly (4vinylpyridine)/multiwalled carbon nanotubes modified glassy carbon electrode. Anal. Chim. Acta 765, 70-76. doi: 10.1016/j.aca.2012.12.039

Goyal, R. N., Gupta, V. K., and Chatterjee, S. (2010). Voltammetric biosensors for the determination of paracetamol at carbon nanotube modified pyrolytic graphite electrode. Sens. Actuators B Chem. 149, 252-258. doi: 10.1016/j.snb.2010.05.019

Goyal, R. N., and Singh, S. P. (2006). Voltammetric determination of paracetamol at C60-modified glassy carbon electrode. Electrochim. Acta 51, 3008-3012. doi: 10.1016/j.electacta.2005.08.036

\section{SUPPLEMENTARY MATERIAL}

The Supplementary Material for this article can be found online at: https://www.frontiersin.org/articles/10.3389/fchem. 2020.594093/full\#supplementary-material

Guo, L., Sun, J., Sun, X., Zhang, J., Hou, L., and Yuan, C. (2019). Construction of $1 \mathrm{D}$ conductive Ni-MOF nanorods with fast $\mathrm{Li}^{+}$kinetic diffusion and stable high-rate capacities as an anode for lithium ion batteries. Nanoscale Adv. 1, 4688-4691. doi: 10.1039/C9NA00616H

Kalambate, P. K., Sanghavi, B. J., Karna, S. P., and Srivastava, A. K. (2015). Simultaneous voltammetric determination of paracetamol and domperidone based on a graphene/platinum nanoparticles/nafion composite modified glassy carbon electrode. Sensor. Actuators B Chem. 213, 285-294. doi: 10.1016/j.snb.2015.02.090

Kang, X., Wang, J., Wu, H., Liu, J., Aksay, I. A., and Lin, Y. (2010). A graphenebased electrochemical sensor for sensitive detection of paracetamol. Talanta 81, 754-759. doi: 10.1016/j.talanta.2010.01.009

Ko, M., Aykanat, A., Smith, M. K., and Mirica, K. A. (2017). Drawing sensors with ball-milled blends of metal-organic frameworks and graphite. Sensors 17:2192. doi: $10.3390 /$ s17102192

Ko, M., Mendecki, L., Eagleton, A. M., Durbin, C. G., Stolz, R. M., Meng, Z., et al. (2020). Employing conductive metal-organic frameworks for voltammetric detection of neurochemicals. J. Am. Chem. Soc. 142, 11717-11733. doi: 10.1021/jacs.9b13402

Krampa, F. D., Aniweh, Y., Kanyong, P., and Awandare, G. A. (2018). Graphene nanoplatelet-based sensor for the detection of dopamine and N-acetyl-p-aminophenol in urine. Arab. J. Chem. 13, 3218-3225. doi: 10.1016/j.arabjc.2018.10.006

Kutluay, A., and Aslanoglu, M. (2013). Modification of electrodes using conductive porous layers to confer selectivity for the voltammetric detection of paracetamol in the presence of ascorbic acid, dopamine and uric acid. Sensor. Actuators. B Chem. 185, 398-404. doi: 10.1016/j.snb.2013.05.025

Laviron, E. (1974). Adsorption, autoinhibition and autocatalysis in polarography and in linear potential sweep voltammetry. J. Electroanal. Chem. Interfacial Electrochem. 52, 355-393. doi 10.1016/S0022-0728(74)80448-1

Laviron, E. (1979). General expression of the linear potential sweep voltammogram in the case of diffusionless electrochemical systems. J. Electroanal. Chem. Interfacial Electrochem. 101, 19-28. doi: 10.1016/S0022-0728(79)80075-3

Ma, B., Martín, C., Kurapati, R., and Bianco, A. (2020). Degradation-by-design: how chemical functionalization enhances the biodegradability and safety of $2 \mathrm{D}$ materials. Chem. Soc. Rev. 49, 6224-6247. doi: 10.1039/C9CS00822E

Miner, E. M., Wang, L., and Dinc ă M. (2018). Modular $\mathrm{O}_{2}$ electroreduction activity in triphenylene-based metal-organic frameworks. Chem. Sci. 9, 6286-6291. doi: 10.1039/C8SC02049C

Raymundo-Pereira, P. A., Campos, A. M., Mendonça, C. D., Calegaro, M. L., Machado, S. A. S., and Oliveira, O. N. (2017). Printex 6L carbon nanoballs used in electrochemical sensors for simultaneous detection of emerging pollutants hydroquinone and paracetamol. Sensor. Actuators B Chem. 252, 165-174. doi: 10.1016/j.snb.2017.05.121

Raymundo-Pereira, P. A., Campos, A. M., Prado, T. M., Furini, L. N., Boas, N. V., Calegaro, M. L., et al. (2016). Synergy between printex nano-carbons and silver nanoparticles for sensitive estimation of antioxidant activity. Anal. Chim. Acta 926, 88-98. doi: 10.1016/j.aca.2016.04.036

Suwannakot, P., Lisi, F., Ahmed, E., Liang, K., Babarao, R., Gooding, J. J., et al. (2020). Metal-organic framework-enhanced solid-phase microextraction mass spectrometry for the direct and rapid detection of perfluorooctanoic acid in environmental water samples. Anal. Chem. 92, 6900-6908. doi: 10.1021/acs.analchem.9b05524

Wan, Q., Wang, X., Yu, F., Wang, X., and Yang, N. (2009). Poly(taurine)/MWNTmodified glassy carbon electrodes for the detection of acetaminophen. J. Appl. Electrochem. 39, 785-790. doi: 10.1007/s10800-008-9721-1

Wang, H., Yuan, B., Yin, T., and Qin, W. (2020). Alternative coulometric signal readout based on a solid-contact ion-selective electrode for detection of nitrate. Anal. Chim. Acta 1129, 136-142. doi: 10.1016/j.aca.2020.07.019 
Xie, L. S., Skorupskii, G., and Dincă M. (2020). Electrically conductive metal-organic frameworks. Chem. Rev. 120, 8536-8580. doi: $10.1021 /$ acs.chemrev.9b00766

Xu, Z., Teng, H., Song, J., Gao, F., Ma, L., Xu, G., et al. (2019). A nanocomposite consisting of $\mathrm{MnO}_{2}$ nanoflowers and the conducting polymer PEDOT for highly sensitive amperometric detection of paracetamol. Microchim. Acta 186:499. doi: 10.1007/s00604-019-3614-3

Yan, M., Ye, J., Zhu, Q., Zhu, L., Huang, J., and Yang, X. (2019). ultrasensitive immunosensor for cardiac troponin I detection based on the electrochemiluminescence of $2 \mathrm{D}$ Ru-MOF nanosheets. Anal. Chem. 91, 10156-10163. doi: 10.1021/acs.analchem. 9b02169

Yuan, B., Sun, P., Zhao, L.-j., Zhang, D., Zhang, Y., Qi, C., et al. (2020). Pd nanoparticles supported on 1,10-phenanthroline-5,6-dione modified graphene oxide as superior bifunctional electrocatalyst for highly sensitive sensing. J. Electroanal. Chem. 861:113945. doi: 10.1016/j.jelechem.2020. 113945

Yuan, B., Wang, H., Cai, J., Peng, Y., Niu, Y., Chen, H., et al. (2019). A novel oxidation-reduction method for highly selective detection of cysteine over reduced glutathione based on synergistic effect of fully fluorinated cobalt phthalocyanine and ordered mesoporous carbon. Sens. Actuators B Chem. 288, 180-187. doi: 10.1016/j.snb.2019. 02.114
Zhang, M., Wang, G., Zheng, B., Li, L., Lv, B., Cao, H., et al. (2019). 3-layer conductive metal-organic nanosheets as electrocatalysts to enable an ultralow detection limit of $\mathrm{H}_{2} \mathrm{O}_{2}$. Nanoscale 11, 5058-5063. doi: 10.1039/C8NR08686A

Zhang, M., Zheng, B.-H., Xu, J., Pan, N., Yu, J., Chen, M., et al. (2018). Fewer-layer conductive metal-organic nanosheets enable ultrahigh mass activity for the oxygen evolution reaction. Chem. Comm. 54, 13579-13582. doi: 10.1039/C8CC08156E

Zhao, P., Ni, M., Chen, C., Zhou, Z., Li, X., Li, C., et al. (2019). Stimuli-enabled switch-like paracetamol electrochemical sensor based on thermosensitive polymer and MWCNTs-GQDs composite nanomaterial. Nanoscale 11, 7394-7403. doi: 10.1039/C8NR09434A

Conflict of Interest: The authors declare that the research was conducted in the absence of any commercial or financial relationships that could be construed as a potential conflict of interest.

Copyright $\odot 2020$ Wang, Liu, Luo, Hou, Song, Niu and Zhang. This is an open-access article distributed under the terms of the Creative Commons Attribution License (CC $B Y)$. The use, distribution or reproduction in other forums is permitted, provided the original author(s) and the copyright owner(s) are credited and that the original publication in this journal is cited, in accordance with accepted academic practice. No use, distribution or reproduction is permitted which does not comply with these terms. 